\title{
New Chiral Ebselen Analogues with Antioxidant and Cytotoxic Potential
}

\author{
Agata J. Pacuła ${ }^{1}$, Katarzyna B. Kaczor ${ }^{2}$, Jędrzej Antosiewicz ${ }^{2,5}$, Anna Janecka ${ }^{3}$, \\ Angelika Długosz ${ }^{3}$, Tomasz Janecki ${ }^{4}$, Andrzej Wojtczak ${ }^{1}$ and Jacek Ścianowski ${ }^{1, *}$ \\ 1 Department of Organic Chemistry, Faculty of Chemistry, Nicolaus Copernicus University, Gagarina 7, \\ 87-100 Torun, Poland; pacula@doktorant.umk.pl (A.J.P.); awojt@umk.pl (A.W.) \\ 2 Department of Bioenergetics and Physiology of Exercise, Medical University of Gdansk, Debinki 1, \\ 80-211 Gdansk, Poland; katarzyna.kaczor@gumed.edu.pl (K.B.K.); jant@gumed.edu.pl (J.A.) \\ 3 Department of Biomolecular Chemistry, Faculty of Medicine, Medical University of Lodz, Mazowiecka 6/8, \\ 92-215 Lodz, Poland; anna.janecka@umed.lodz.pl (A.J.); angelika.dlugosz@stud.umed.lodz.pl (A.D.) \\ 4 Institute of Organic Chemistry, Lodz University of Technology, Zeromskiego 116, 90-924 Lodz, Poland; \\ tomasz.janecki@p.lodz.pl \\ 5 Department of Biochemistry, Gdansk University of Physical Education and Sport, Kazimierza Gorskiego 1, \\ 80-336 Gdansk, Poland \\ * Correspondence: jsch@chem.umk.pl; Tel.: +48-566-114-532
}

Academic Editors: Claudio Santi, Luana Bagnoli and Roman Dembinski

Received: 30 January 2017; Accepted: 17 March 2017; Published: 20 March 2017

\begin{abstract}
New chiral camphane-derived benzisoselenazol-3(2H)-ones and corresponding diselenides have been synthetized using a convenient one-pot procedure. Se-N bond was efficiently converted to an Se-Se bond, which could also be easily re-oxidized to the initial benzisoselenazolone moiety. The antioxidant activity of camphor derivatives was evaluated and compared to the reactivity of a series of $\mathrm{N}$-amino acid benzisoselenazol-3(2H)-ones obtained by a modified procedure involving the improved synthesis and isolation of the diseleno bis(dibenzoic) acid. The most efficient peroxide scavengers, $\mathrm{N}$-bornyl and $\mathrm{N}$-leucine methyl ester benzisoselenazol-3(2H)-ones, were further evaluated as cytotoxic agents on four cancer cell lines (MCF-7, HEP G2, HL 6, and DU 145) and normal cell line PNT1A. The highest antiproliferative potential was evaluated for two compounds bearing a 3-methylbutyl carbon chain, $\mathrm{N}$-leucine methyl ester and $\mathrm{N}$-3-methylbutyl benzisoselenazol-3(2H)-ones.
\end{abstract}

Keywords: organoselenium compounds; terpenes; antioxidant activity; biological activity

\section{Introduction}

Since it was proven that selenium is an essential micronutrient mainly associated with the antioxidant defense system of the living cell, the discovery of ebselen ( $N$-phenylbenzisoselenazol-3(2H)-one) $\mathbf{1}$ has been considered a milestone in this constantly developing field of research [1]. This organoselenium compound is able to act as selenocysteine (Sec), thus mimicking the activity of glutathione peroxidase (GPx). Sec is the key element of the enzymes active site that provides GPx with the unique ability to reduce hydrogen peroxide and other reactive oxygen and nitrogen species [2]. This unique property makes ebselen a potent bioactive molecule which is effective in the treatment of various diseases including diabetes [3-6], Alzheimer's disease [7], stroke [8], hearing loss [9], and cancer [10]. It is also non-toxic, as the selenium atom incorporated in its structure is not bioavailable [11].

The mechanism of peroxides reduction by ebselen $\mathbf{1}$ is controversial and several activity pathways have been proposed. It was postulated that the elimination of peroxide is performed by a specific active species, formed from ebselen $\mathbf{1}$. According to different assays, 1 can be transformed into selenol 2 [12] 
or diselenide 3 [13], which can reduce hydrogen peroxide forming selenic acid 4 . Elimination of water from acid 4 regenerates ebselen $\mathbf{1}$ (Scheme 1).

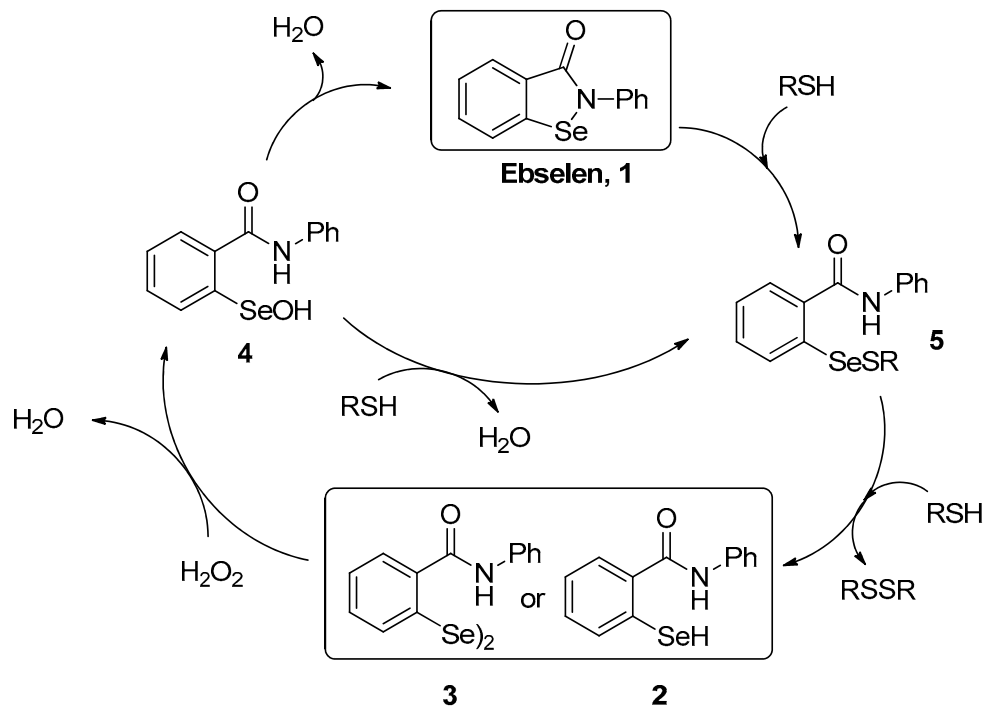

Scheme 1. Probable catalytic pathways for the reduction of $\mathrm{H}_{2} \mathrm{O}_{2}$ by ebselen.

In both cases, the rate determining the step of the cycle is the cleavage of the Se-S bond, in the selenenylsulfide 5 and the formation of the active organoselenium species $\mathbf{2}$ or $\mathbf{3}$. Our recent studies confirmed this assumption, showing that ebselen derivatives undergo facile Se-N bond cleavage and rapidly form the corresponding diselenides, exhibiting high antioxidant potential [14]. To further examine this issue, we synthesized a series of new chiral ebselen derivatives, transformed them to corresponding diselenides, and compared their antioxidant activity. It seems probable that the direct application of a diselenide could increase the rate of peroxide reduction.

So far, the synthesis of $N$-phenylbenzisoselenazol-3(2H)-one 1 has been accomplished by a multi-step synthesis based on the formation of 2,2-diselenobis(benzoic acid) 6, followed by the conversion to corresponding dichloride 7 with thionyl chloride and further reaction with aniline (Method A) [15] or 0 -metalation of benzamide 8, selenium insertion, and oxidative cyclization promoted by copper bromide (Method B) [16]. Several methods in which $N$-phenyl-o-iodobenzamide 9 is used as a starting material are described. Ebselen 1 was obtained by treatment with a copper catalyst and selenium in the presence of potassium carbonate as a base (Method C) [17], a nucleophilic reagent formed from selenium and potassium tert-butoxide (Method D) [18] or by the methodology presented in our previous paper, in which lithium diselenide, formed in the reaction of lithium hydroxide and elemental selenium in the presence of hydrazine hydrate, is applied (Method E) [19] (Scheme 2).



Scheme 2. Methodologies to synthesize ebselen 1. 
Although various benzisoselenazolones have been synthetized and tested as bio-molecules, there are only few examples of chiral ebselen derivatives [18,20-22]. The aim of our research was to fill this gap and combine the benzisoselenazolone structure with a chiral terpene scaffold. Terpenes possess several significant properties. As natural products abundant in plants, they provide a broad spectrum of structurally diverse motifs and were used not only as fragrance or taste carriers but also as pharmacologically potent agents [23]. In our research group, we efficiently used terpenes to obtain a broad spectrum of various chiral organoselenium derivatives including selenols, selenides, and diselenides [24-31].

Herein, we report the synthesis of benzisoselenazolones and corresponding diselenides substituted on the nitrogen atom with monoterpene skeletons from camphane group. We also tested the obtained compounds for their antioxidant and anticancer activity. Obtained results were additionally compared to the activity of a series of other chiral, naturally derived benzisoselenazolones bearing amino acid substituents.

\section{Results and Discussion}

In the conducted research, we planned to use and compare the efficiency of two metal-free procedures (method D and E) in the synthesis of new camphane-derived benzisoselenazolones and corresponding diselenides. The first step included the synthesis of $\mathrm{N}$-terpenyl-o-iodobenzamides 15 and 16 used as substrates. $R(-)$-Isobornylamine 12 was obtained from camphor by a three-step procedure consisting of formation of corresponding oxime 10, its conversion to oxime methyl ether 11, and reduction of $\mathbf{1 1}$ with lithium aluminium hydride to amine 12. During the reduction of oxime methyl ether, we observed the formation of isobornyl amine 12 and bornyl amine 13 (64:36). Isobornyl amine 12 was separated by column chromatography (silica gel, dichloromethane). Iodobenzamides $\mathbf{1 5}$ and 16 were obtained from the reaction of acid chloride 14 with previously synthetized amine 12 and commercially available $R(+)$-bornylamnie 13 (Scheme 3).

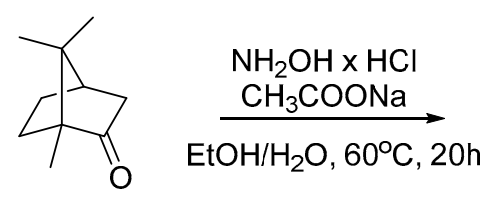

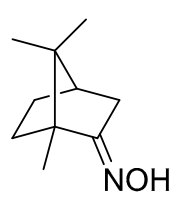

$10,88 \%$

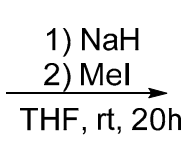

$\underset{\mathrm{THF}, \mathrm{rt}, 20 \mathrm{~h}}{\stackrel{\mathrm{Mel}}{\longrightarrow}}$

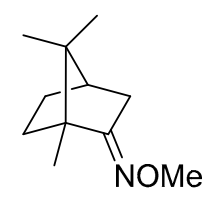

$11,75 \%$

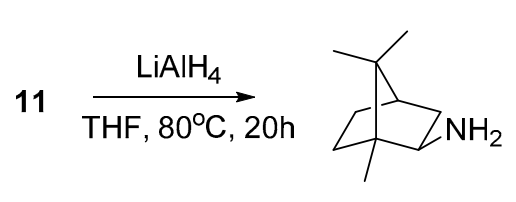

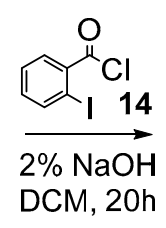<smiles>CC12CCC(CC(NC(=O)c3ccccc3I)C1)C2(C)C</smiles>

$15,92 \%$

$12,30 \%$
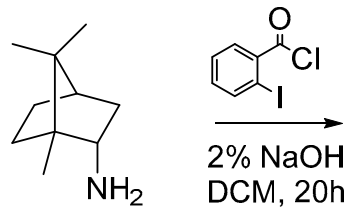

13

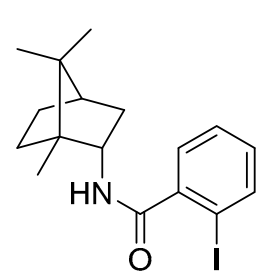

$16,95 \%$

Scheme 3. Synthesis of $N$-isobornyl and N-bornyl-o-iodobenzamides 15 and $\mathbf{1 6}$.

In the next step, we decided to obtain benzisoselenazolones by the reaction of amides $\mathbf{1 5}$ and $\mathbf{1 6}$ with nucleophilic reagent formed in situ from elemental selenium and potassium tert-butoxide (Method D). Unfortunately, corresponding diselenides $\mathbf{1 7}$ and $\mathbf{1 8}$ were obtained in low yields (Scheme 4). 


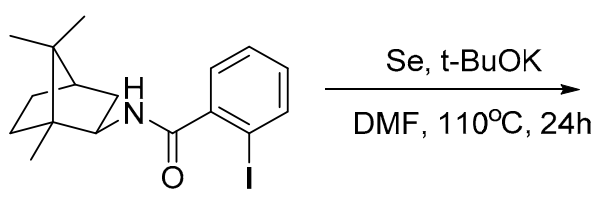

15<smiles>CC1(C)C2CCC1(C)C(NC(=O)c1ccccc1I)C2</smiles>

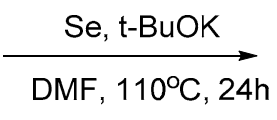<smiles>CC1(C)C2CCC1(C)C(NC(=O)c1ccccc1S(=O)(=O)O)C2</smiles>

$17,20 \%$<smiles>CC1(C)C2CCC1(C)C(NC(=O)c1ccccc1S(=O)(=O)O)C2</smiles>

16

$18,18 \%$

Scheme 4. Synthesis of diselenides $\mathbf{1 7}$ and $\mathbf{1 8 .}$

These results prompted us to modify the procedure and design a new methodology in which the nucleophile was changed to lithium diselenide, formed from lithium hydroxide and elemental selenium in the presence of hydrazine hydrate. To our delight, this modification gave expected benzisoselenazolones 19 and $\mathbf{2 0}$ in high yields. The structure of compound $\mathbf{2 0}$ was additionally confirmed by an X-ray analysis (Scheme 5).<smiles>CC12CCC(C)(C1)C(NC(=O)c1ccccc1I)C2</smiles>

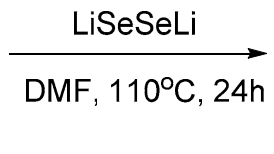<smiles>CC1(C)C2CCC1(C)C(NC(=O)c1ccccc1I)C2</smiles>

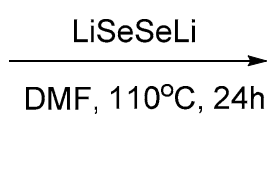<smiles>CC1(C)C2CCC(C)(C2)[Se]2c3ccccc3C(=O)NC21</smiles>

$19,92 \%$<smiles>CC1(C)C2CCC1(C)C(n1[se]c3ccccc3c1=O)C2</smiles>

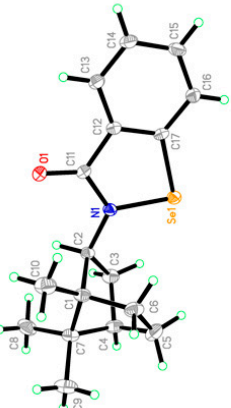

$20,90 \%$

Structure of compound 20

Scheme 5. Synthesis of $N$-isobornyl and $N$-bornyl benzisoselenazol-3(2H)-ones 19 and 20.

The absolute configuration of compound 20, determined by the Flack method [32] is $(1 R, 2 S, 4 R)$. The bulk of the $N$-bornyl moiety seems to be the largest among the chiral benzisoselenazolones reported so far $[13,15]$. Two bonds formed by Se1 are almost identical, with the Se1-N1 and Se1-C17 distances being 1.883(2) and 1.887(2) $\AA$, respectively and the N1-Se1-C17 angle is 85.89(10) deg. These values are similar to those found for other chiral derivatives. However, a search in the Cambridge Structural Database [33] revealed that N-Se-C angle values range from 77.05 to $90.39 \mathrm{deg}$, with the smaller angles for compounds having the additional substituent at Se atom. Comparison revealed that Se-N and Se-C bond distances reported here were significantly longer than those Se-C 1.868(4) and Se-N 1.870(5) Å reported for the analog containing two ebselen moieties linked by ethylene bridge [34]. In that structure, the C-Se-N angle of 84.97(18) is significantly smaller than that in the structure reported here. In selenoxide, analog of ebselen [35], the Se-N and Se-C bonds of 1.899(3) and 1.928(3) $\AA$, respectively, are longer than those found in compound 20 reported here. Also, the N-Se-C angle 84.68(13) deg was significantly smaller than that in 20. In the structure of ebselen with no substituent at $\mathrm{N}$ [36], 
the significant difference up to $0.039 \AA$ A was reported for Se-N and Se-C distances, and the C-Se-N angle was significantly smaller than in the structure reported here. However, geometry of N-Se-C fragment in compound containing $\mathrm{N}$-Met [37] was almost identical with that reported here. That might result from the steric and electronic effect of $\mathrm{Se}=\mathrm{O}$ bond in selenoxide. Contrary to this, the values of Se-C 1.856(2), Se1-N 1.916(2) and C-Se-N 84.33(10) reported for of ebselen [38] differed significantly from those in the structure reported here. The comparison given above indicates that the electronic effect and not only the bulk or nature of $\mathrm{N}$-substituent affect the ebselen geometry in a significant manner. Geometry of the bornyl moiety is typical for such systems. Conformation of the molecule is described with Se1-N1-C2-C1 and Se1-N1-C2-C3 torsion angles being 93.9(2) and -27.7(3) deg, respectively. See detailed information about NMR spectra and crystallographic data in Supplementary Materials.

Benzisoselenazolones 19 and 20 were further quantitatively converted to corresponding diselenides 17 and 18 using sodium borohydride. On the other hand, the Se-N bond could be efficiently regenerated in the reaction with potassium iodate used as an oxidant (Scheme 6).

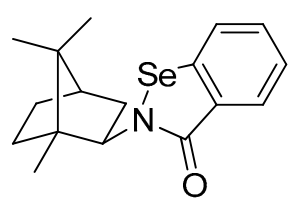

19

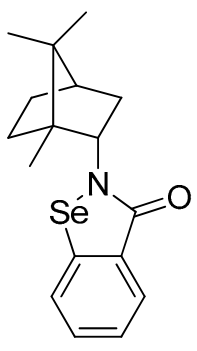

20
1) $\mathrm{NaBH}_{4} / \mathrm{MeOH} / \mathrm{Ar}$

2) $\mathrm{H}_{2} \mathrm{O} /$ air

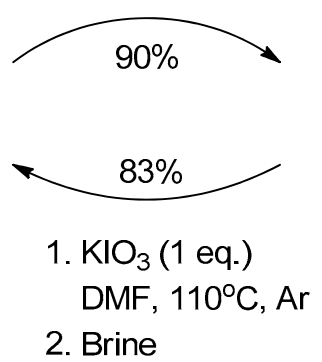

1) $\mathrm{NaBH}_{4} / \mathrm{MeOH} / \mathrm{Ar}$

2) $\mathrm{H}_{2} \mathrm{O} / \mathrm{air}$

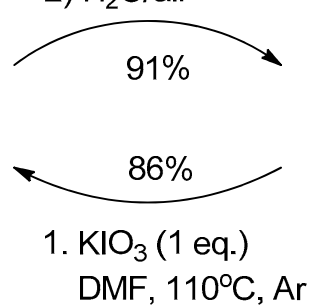

2. Brine<smiles>CC1(C)C2CCC1(C)C(NC(=O)c1ccccc1S(=O)(=O)O)C2</smiles>

17

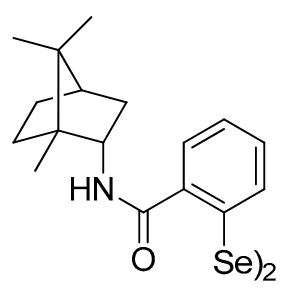

18

Scheme 6. Cleavage and regeneration of Se-N bond.

To compare the biological activity of the synthetized compounds to other chiral ebselen analogues, a series of amino acid derivatives was obtained and similarly evaluated. To achieve this goal, several amino acid methyl esters were converted into $\mathrm{N}$-substituted-o-iodobenzamides. Conversion to the final organoselenium derivatives using the methodology developed in our research group (Method E) was unsuccessful due to the hydrolysis of the ester moiety. As procedures involving cyclization of iodobenzamides using nucleophilic selenium reagents could not be used, we focused on the commonly used multistep Method A. During this investigation, we developed a revised version of this method, i.e., a convenient procedure to obtain the 2,2-diselenobis(benzoic acid) 6 . Synthesis of 6 significantly limits the overall yield of the reaction, thus improving the efficiency of this step highly upgrades the methodology. Acid $\mathbf{6}$ is usually prepared from the diazonium salt of anthranilic acid followed by substitution with sodium diselenide. The yield of the reaction depends on the procedure by which sodium diselenide is formed and by the efficiency of the final product isolation. Sodium diselenide can be prepared using different reagents, elemental selenium and sodium hydroxide in the presence of hydrazine in methanol [39], with addition of rongalite in water [40] or from elemental 
selenium and sodium borohydride in water, with or without $\mathrm{NaOH}[41,42]$. We turned our attention to the last procedure, in which sodium diselenide is synthesized from Se and $\mathrm{NaBH}_{4}$ in $\mathrm{NaOH}_{\mathrm{aq}}$. By changing the reaction conditions, i.e., lower temperature and longer reaction time, we were able to obtain pure $\mathrm{Na}_{2} \mathrm{Se}_{2}$, eliminating the common formation of $\mathrm{Na}_{2} \mathrm{Se}$. Next, we optimized the purification procedure of the final product. Synthesized 2,2-diselenobis(benzoic acid) 6 is often contaminated with salicylic acid which is hard to separate. Multiple rinsing of the crude product with boiling water enabled to obtain the final product as pure solid in $90 \%$ yield.

The revised procedure (Method A) was used to synthesize $N$-substituted benzisoselenazol-3(2H)-ones derived from glycine 21, $L$-alanine 22, $L$-leucine $\mathbf{2 3}, L$-phenylalanine 24 and $\beta$-alanine 25 [22] (Scheme 7 ).

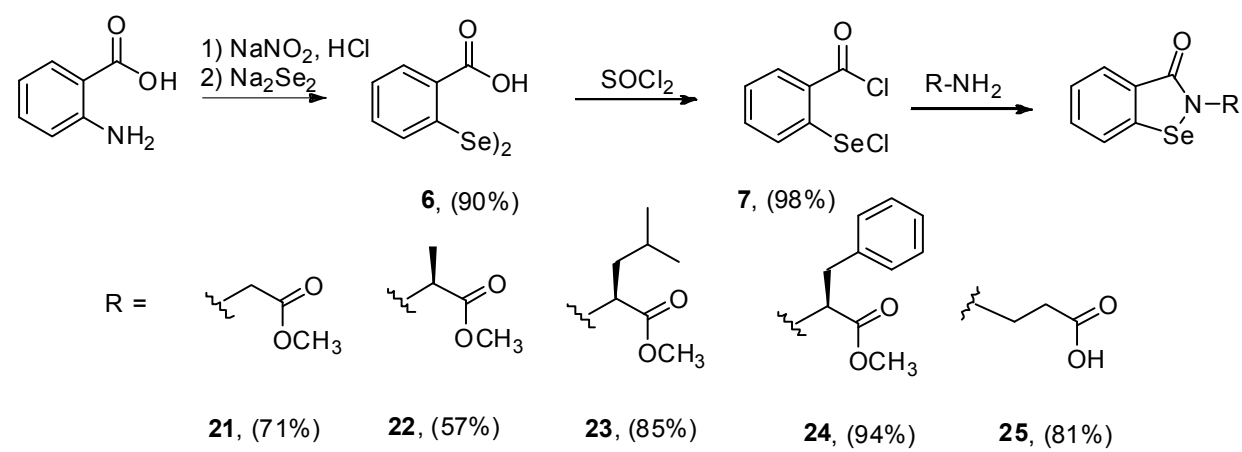

Scheme 7. Synthesis of amino acid derivatives 21-25.

All obtained terpene and amino acid derivatives were tested as antioxidants using NMR activity assay proposed by Iwaoka and co-workers. The ability to eliminate hydrogen peroxide was equal to the rate of the oxidation of dithiol to disulfide. Formation of the product was observed by ${ }^{1} \mathrm{H}-\mathrm{NMR}$ spectra performed in selected time intervals [43]. The results are presented in Table 1.

Table 1. Results of the antioxidant activity measurement.

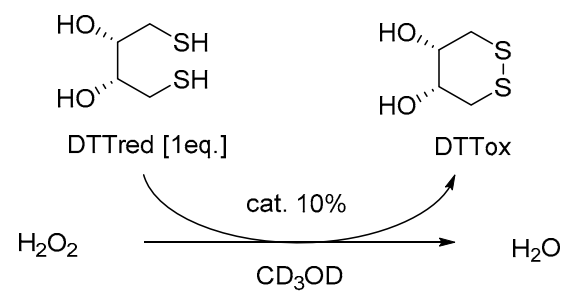

\begin{tabular}{cccccc}
\hline & \multicolumn{5}{c}{ Remaining Dithiotreitol (\%) } \\
\hline Catalyst & $\mathbf{3} \mathbf{~} \mathbf{\text { in }}$ & $\mathbf{5} \mathbf{~} \mathbf{m i n}$ & $\mathbf{1 5} \mathbf{~} \mathbf{\text { in }}$ & $\mathbf{3 0} \mathbf{~} \mathbf{\text { in }}$ & $\mathbf{6 0} \mathbf{~} \mathbf{\text { in }}$ \\
\hline $\mathbf{1 7}$ & 59 & 36 & 12 & 0 & 0 \\
$\mathbf{1 8}$ & 48 & 38 & 28 & 25 & 22 \\
$\mathbf{1 9}$ & 50 & 17 & 0 & 0 & 0 \\
$\mathbf{2 0}$ & 30 & 11 & 0 & 0 & 0 \\
$\mathbf{2 1}$ & 99 & 99 & 98 & 97 & 95 \\
$\mathbf{2 2}$ & 96 & 95 & 93 & 91 & 89 \\
$\mathbf{2 3}$ & 45 & 0 & 0 & 0 & 0 \\
$\mathbf{2 4}$ & 96 & 95 & 94 & 93 & 90 \\
$\mathbf{2 5}$ & 94 & 93 & 92 & 92 & 91 \\
$\mathbf{2 6}$ & 77 & 58 & 42 & 28 & 13 \\
Ebselen (1) & 84 & 75 & 64 & 58 & 52 \\
Diselenide (3) & 89 & 83 & 74 & 68 & 63 \\
\hline
\end{tabular}

The highest reactivity was found for $N$-bornyl 20 and $N$-leucine methyl ester 23 benzisoselenazol-3(2H)-ones. Total conversion of DTT ${ }^{\text {red }}$ to DTT ${ }^{\text {ox }}$ (DDT-Dithiotreitol) was observed 
after 5 and $3 \mathrm{~min}$, respectively. Other terpene derivatives 17-19 exhibited much lower antioxidant potential, and no antioxidant potential was observed for other amino acid benzisoselenazolones. This result led us to the conclusion that the structure of leucine, bearing a 2-methylpropyl chain on the $\alpha$-carbon, could be the reason of this high reactivity. Thus, for further anticancer activity assays, we chose to evaluate the cytotoxic potential of compounds 20 and 23, for which the best results were obtained in the NMR activity test.

Additionally, we decided to test the anticancer activity of $\mathrm{N}$-3-methylbutyl benzisoselenazol-3(2H)-one 26 presented in our previous paper [19], bearing a carbon chain analogous to the one present in the structure of leucine. The cytotoxic activity was evaluated on four cancer cell lines: MCF-7 (breast carcinoma), HEP G2 (liver cancer), HL60 (human promyelocytic leukemia), DU 145 (prostate cancer), and non-cancerous cell line PNT1A. The results are collected in Table 2.

Table 2. Results of the cytotoxic activity assays.

\begin{tabular}{|c|c|c|c|c|c|c|}
\hline Comp. & Structure & $\begin{array}{l}\text { MCF-7 } \\
\text { (MTT) }\end{array}$ & $\begin{array}{c}\text { HEP G2 } \\
\text { (MTT) }\end{array}$ & $\begin{array}{l}\text { HL60 } \\
\text { (MTT) }\end{array}$ & $\begin{array}{c}\text { DU-145 } \\
\text { (SRB) }\end{array}$ & $\begin{array}{c}\text { PNT1A } \\
\text { (SRB) }\end{array}$ \\
\hline & & \multicolumn{5}{|c|}{$\mathrm{IC}_{50}, \mu \mathrm{M}$} \\
\hline 20 & & $220 \pm 34$ & $232 \pm 28$ & $190 \pm 20$ & $>40$ & $>40$ \\
\hline 23 & & $18 \pm 1.1$ & $23.5 \pm 3.2$ & $21.5 \pm 1.8$ & $>40$ & $>40$ \\
\hline 26 & & $29 \pm 1.9$ & $100 \pm 12$ & $43.5 \pm 5.0$ & $30.6 \pm 0.2$ & $30.35 \pm 0.06$ \\
\hline Control & Carboplatin & $0.70 \pm 0.30$ & $3.19 \pm 0.46$ & $9.70 \pm 1.20$ & ----- & ----- \\
\hline
\end{tabular}

The highest antiproliferative activity was observed for $N$-leucine methyl ester derivative 23 against MCF-7, HEP G2, and HL60 cells. This compound also exhibited the best antioxidant potential. Its activity against MCF-7, HEP G2, and HL60 was relatively good and was compared with the data obtained for carboplatin. Structurally similar N-3-methylbutyl benzisoselenazol-3(2H)-one $\mathbf{2 6}$ was also active against all three cancer cell lines and had low cytotoxicity in HEP G2 cell line, on the contrary to data obtained on chiral $N$-bornyl derivative 20, revealing that the presence of $\alpha$-carbon 2-methylpropyl chain could be a structural motif providing the bio-activity.

\section{Experimental}

\subsection{General}

${ }^{1} \mathrm{H}-\mathrm{NMR}$ spectra were obtained at 400 or $700 \mathrm{MHz}$ and chemical shifts were recorded relative to $\mathrm{SiMe}_{4}(\delta 0.00)$ or solvent resonance $\left(\mathrm{CDCl}_{3} \delta 7.26, \mathrm{CD}_{3} \mathrm{OD} \delta 3.31\right)$. Multiplicities were given as $\mathrm{s}$ (singlet), d (doublet), dd (double doublet), ddd (double double doublet), $\mathrm{t}$ (triplet), td (triple doublet), $\mathrm{dt}$ (double triplet), and $\mathrm{m}$ (multiplet). The number of protons (n) for a given resonance was indicated by $n \mathrm{H}$. Coupling constants were reported as a J value in Hz. ${ }^{13} \mathrm{C}-\mathrm{NMR}$ spectra were acquired at $100.6 \mathrm{MHz}$ and chemical shifts were recorded relative to solvent resonance $\left(\mathrm{CDCl}_{3} \delta 77.25\right)$. NMR spectra were carried out using ACD/NMR Processor Academic Edition (Advanced Chemistry Development, Toronto, ON, Canada). Original NMR spectra and crystallographic data are included in SM. Commercially available solvents DMF ( $N, N$-dimethylformamide), DCM (dichloromethane), and MeOH (Sigma Aldrich, 
St. Louis, MO, USA), and chemicals were used without further purification. Column chromatography was performed using Merck 40-63D 60 Å silica gel (Merck, Darmstadt, Germany).

\subsection{Procedures and Analysis Data}

\subsection{1. (1R)-Camphor Oxime (10)}

To a solution of hydroxylamine hydrochloride $(0.164 \mathrm{~mol})$ and sodium acetate $(0.197 \mathrm{~mol})$ in water $(100 \mathrm{~mL}),(+)$-camphor $(0.131 \mathrm{~mol})$ dissolved in ethanol $(65 \mathrm{~mL})$ was added. The mixture was stirred at $60{ }^{\circ} \mathrm{C}$ for $20 \mathrm{~h}$. Ethanol was evaporated and the precipitated oxime filtrated under reduce pressure. The product was used without further purification [44].

Yield: $88 \%,{ }^{1} \mathrm{H}-\mathrm{NMR}\left(400 \mathrm{MHz}, \mathrm{CDCl}_{3}\right) \delta=0.82\left(\mathrm{~s}, 3 \mathrm{H}, \mathrm{CH}_{3}\right), 0.94\left(\mathrm{~s}, 3 \mathrm{H}, \mathrm{CH}_{3}\right), 1.02\left(\mathrm{~s}, 3 \mathrm{H}, \mathrm{CH}_{3}\right)$, $1.20-1.30(\mathrm{~m}, 1 \mathrm{H}), 1.43-1.52(\mathrm{~m}, 1 \mathrm{H}), 1.72(\mathrm{td}, J=4.0,12.4 \mathrm{~Hz}, 1 \mathrm{H}), 1.80-1.91(\mathrm{~m}, 1 \mathrm{H}), 1.93(\mathrm{t}, J=4,4 \mathrm{~Hz}, 1 \mathrm{H})$, $2.07(\mathrm{~d}, J=18.0 \mathrm{~Hz}, 1 \mathrm{H}), 2.57(\mathrm{dt}, J=4.4,18.0 \mathrm{~Hz}, 1 \mathrm{H}) \mathrm{ppm}$.

\subsection{2. (1R)-Camphor O-methyloxime (11)}

To a suspension of sodium hydride $(0.183 \mathrm{~mol})$ in anhydrous petroleum ether a solution of (1R)-Camphor oxime 10 (0.093 mol) in anhydrous THF $(90 \mathrm{~mL})$ was added portionwise. The mixture was stirred for $0.5 \mathrm{~h}$ at room temperature and methyl iodide $(0.111 \mathrm{~mol})$ was added. The mixture was stirred for additional $20 \mathrm{~h}$. THF was evaporated, and the formed precipitate was washed with water $(50 \mathrm{~mL})$ and extracted with petroleum ether $(2 \times 50 \mathrm{~mL})$. Combined organic layers were dried over anhydrous magnesium sulphate and evaporated. The product was used without further purification [45].

Yield: $75 \%,{ }^{1} \mathrm{H}-\mathrm{NMR}\left(700 \mathrm{MHz}, \mathrm{CDCl}_{3}\right) \delta=0.82\left(\mathrm{~s}, 3 \mathrm{H}, \mathrm{CH}_{3}\right), 0.94\left(\mathrm{~s}, 3 \mathrm{H}, \mathrm{CH}_{3}\right), 1.04\left(\mathrm{~s}, 3 \mathrm{H}, \mathrm{CH}_{3}\right)$, $1.20-1.30(\mathrm{~m}, 1 \mathrm{H}), 1.43-1.52(\mathrm{~m}, 1 \mathrm{H}), 1.72(\mathrm{td}, J=4.0,12.4 \mathrm{~Hz}, 1 \mathrm{H}), 1.82-1.88(\mathrm{~m}, 1 \mathrm{H}), 1.90(\mathrm{t}, J=4.2 \mathrm{~Hz}, 1 \mathrm{H})$, $2.07(\mathrm{~d}, J=18.2 \mathrm{~Hz}, 1 \mathrm{H}), 2.49(\mathrm{dt}, J=7.7,17.5 \mathrm{~Hz}, 1 \mathrm{H}), 3.85\left(\mathrm{~s}, \mathrm{OCH}_{3}, 3 \mathrm{H}\right) \mathrm{ppm}$.

\subsection{3. (R)-(-)-Isobornylamine (12)}

To a suspension of $\mathrm{LiAlH}_{4}(0.066 \mathrm{~mol})$ in anhydrous THF $(50 \mathrm{~mL})$ a solution of $(1 R)$-camphor O-methyloxime $11(0.33 \mathrm{~mol})$ in THF $(25 \mathrm{~mL})$ was slowly added. The mixture was stirred under reflux for $24 \mathrm{~h}$. After cooling to room temperature $\mathrm{H}_{2} \mathrm{O}(2 \mathrm{~mL}), 10 \% \mathrm{NaOH}(3 \mathrm{~mL})$ and $\mathrm{H}_{2} \mathrm{O}(6 \mathrm{~mL})$ were added dropwise. The formed suspension was extracted with diethyl ether. Combined organic layers were dried and evaporated under reduce pressure. The crude product was isolated by column chromatography (silica gel, DCM).

Yield: $30 \%,{ }^{1} \mathrm{H}-\mathrm{NMR}\left(700 \mathrm{MHz}, \mathrm{CDCl}_{3}\right) \delta=0.84\left(\mathrm{~s}, 3 \mathrm{H}, \mathrm{CH}_{3}\right), 0.89\left(\mathrm{~s}, 3 \mathrm{H}, \mathrm{CH}_{3}\right), 0.99\left(\mathrm{~s}, 3 \mathrm{H}, \mathrm{CH}_{3}\right)$, $1.00-1.05(\mathrm{~m}, 1 \mathrm{H}), 1.08-1.12(\mathrm{~m}, 1 \mathrm{H}), 1.52-1.59(\mathrm{~m}, 4 \mathrm{H}), 1.67-1.72(\mathrm{~m}, 2 \mathrm{H}), 1.77(\mathrm{dd}, J=8.4,12.6 \mathrm{~Hz}, 1 \mathrm{H})$, $2.74(\mathrm{dd}, J=4.9,9.1 \mathrm{~Hz}, 1 \mathrm{H}) \mathrm{ppm}$.

\subsubsection{General Procedure for the Synthesis of Compounds 15 and $\mathbf{1 6}$}

To a solution of an amine $(1.0 \mathrm{mmol})$ in DCM $(2 \mathrm{~mL}), 4.4 \mathrm{~mL}$ of $2 \% \mathrm{NaOH}$ was added. The mixture was cooled to $0{ }^{\circ} \mathrm{C}$ and $o$-iodobenzoic acid chloride $(1.1 \mathrm{mmol})$ dissolved in DCM $(3 \mathrm{~mL})$ was added dropwise. After stirring at room temperature for $20 \mathrm{~h}$, the product was extracted with DCM, and combined organic layers were washed with $10 \% \mathrm{NaHCO}_{3}$ and dried over magnesium sulphate. The solvent was removed under reduce pressure to obtain the product as white solid.

N-Isobornyl-o-iodobenzamide (15). Yield: $92 \%$, $[\alpha]_{\mathrm{D}}^{25}=-73.0\left(c 1, \mathrm{CHCl}_{3}\right),{ }^{1} \mathrm{H}-\mathrm{NMR}\left(400 \mathrm{MHz}, \mathrm{CDCl}_{3}\right)$ $\delta=0.83\left(\mathrm{~s}, 3 \mathrm{H}, \mathrm{CH}_{3}\right), 0.90\left(\mathrm{~s}, 3 \mathrm{H}, \mathrm{CH}_{3}\right), 0.95\left(\mathrm{~s}, 3 \mathrm{H}, \mathrm{CH}_{3}\right), 1.14-1.22(\mathrm{~m}, 1 \mathrm{H}), 1.31-1.38(\mathrm{~m}, 1 \mathrm{H})$, $1.55-1.65(\mathrm{~m}, 1 \mathrm{H}), 1.65-1.77(\mathrm{~m}, 3 \mathrm{H}), 1.93(\mathrm{dd}, J=8.4,12.0 \mathrm{~Hz}, 1 \mathrm{H}), 4.07(\mathrm{dt}, J=4.8,8.8 \mathrm{~Hz}, 1 \mathrm{H})$, $5.75(\mathrm{~d}, J=8.0 \mathrm{~Hz}, 1 \mathrm{H}, \mathrm{NH}), 7.01-7.09\left(\mathrm{~m}, 1 \mathrm{H}_{\mathrm{ar}}\right), 7.30-7.35\left(\mathrm{~m}, 2 \mathrm{H}_{\mathrm{ar}}\right), 7.80\left(\mathrm{~d}, J=7.6 \mathrm{~Hz}, 1 \mathrm{H}_{\mathrm{ar}}\right) \mathrm{ppm}$; ${ }^{13} \mathrm{C}-\mathrm{NMR}\left(100.6 \mathrm{~Hz}, \mathrm{CDCl}_{3}\right) \delta=12.2\left(\mathrm{CH}_{3}\right), 20.2\left(\mathrm{CH}_{3}\right), 20.5\left(\mathrm{CH}_{3}\right), 27.0\left(\mathrm{CH}_{2}\right), 36.0\left(\mathrm{CH}_{2}\right), 38.9\left(\mathrm{CH}_{2}\right)$, 
$44.9(\mathrm{CH}), 47.2(\mathrm{C}), 48.8(\mathrm{C}), 57.4(\mathrm{CH}), 92.3(\mathrm{Car}), 128.2\left(\mathrm{CH}_{\mathrm{ar}}\right), 128.3\left(\mathrm{CH}_{\mathrm{ar}}\right), 130.9\left(\mathrm{CH}_{\mathrm{ar}}\right), 139.9\left(\mathrm{CH}_{\mathrm{ar}}\right)$, $142.6\left(\mathrm{C}_{\mathrm{ar}}\right), 168.7(\mathrm{C}=\mathrm{O}) \mathrm{ppm}$; Elemental Anal. Calcd for $\mathrm{C}_{17} \mathrm{H}_{22} \mathrm{INO}$ (383.267): $\mathrm{C}$, 53.27; H, 5.79. Found: $\mathrm{C}, 53.08 ; \mathrm{H}, 5.81$.

N-Bornyl-o-iodobenzamide (16). Yield: 95\%, m.p. $119-121{ }^{\circ} \mathrm{C},[\alpha]_{\mathrm{D}}^{25}=+21.5$ (c $\left.1, \mathrm{CHCl}_{3}\right),{ }^{1} \mathrm{H}-\mathrm{NMR}$ $\left(700 \mathrm{MHz}, \mathrm{CDCl}_{3}\right) \delta=0.90\left(\mathrm{~s}, 3 \mathrm{H}, \mathrm{CH}_{3}\right), 0.97\left(\mathrm{~s}, 3 \mathrm{H}, \mathrm{CH}_{3}\right), 1.00\left(\mathrm{~s}, 3 \mathrm{H}, \mathrm{CH}_{3}\right), 1.17-1.22(\mathrm{~m}, 1 \mathrm{H})$, $1.42-1.47(\mathrm{~m}, 1 \mathrm{H}), 1.54-1.60(\mathrm{~m}, 3 \mathrm{H}), 1.71(\mathrm{t}, J=4.2 \mathrm{~Hz}, 1 \mathrm{H}), 1.78-1.83(\mathrm{~m}, 1 \mathrm{H}), 4.42-4.46(\mathrm{~m}, 1 \mathrm{H})$, $5.75(\mathrm{~d}, J=7.0 \mathrm{~Hz}, 1 \mathrm{H}, \mathrm{NH}), 7.10\left(\mathrm{dt}, J=2.1,7.7 \mathrm{~Hz}, 1 \mathrm{H}, 1 \mathrm{H}_{\mathrm{ar}}\right), 7.37-7.42\left(\mathrm{~m}, 2 \mathrm{H}_{\mathrm{ar}}\right), 7.87(\mathrm{dd}, J=0.7$, $\left.7.7 \mathrm{~Hz}, 1 \mathrm{H}_{\mathrm{ar}}\right) \mathrm{ppm} ;{ }^{13} \mathrm{C}-\mathrm{NMR}\left(100.6 \mathrm{~Hz}, \mathrm{CDCl}_{3}\right) \delta=13.9\left(\mathrm{CH}_{3}\right), 18.7\left(\mathrm{CH}_{3}\right), 19.8\left(\mathrm{CH}_{3}\right), 28.1\left(\mathrm{CH}_{2}\right)$, $28.3\left(\mathrm{CH}_{2}\right), 37.4\left(\mathrm{CH}_{2}\right), 44.9(\mathrm{CH}), 48.3(\mathrm{C}), 49.6(\mathrm{C}), 54.6(\mathrm{CH}), 92.3\left(\mathrm{C}_{\mathrm{ar}}\right), 128.1\left(\mathrm{CH}_{\mathrm{ar}}\right), 128.4\left(\mathrm{CH}_{\mathrm{ar}}\right)$, $130.9\left(\mathrm{CH}_{\mathrm{ar}}\right), 139.8\left(\mathrm{CH}_{\mathrm{ar}}\right), 142.9\left(\mathrm{C}_{\mathrm{ar}}\right), 169.9(\mathrm{C}=\mathrm{O}) \mathrm{ppm}$; Elemental Anal. Calcd for $\mathrm{C}_{17} \mathrm{H}_{22} \mathrm{INO}$ (383.267): C, 53.27; H, 5.79. Found: $C, 53.13 ; H, 5.85$.

\subsubsection{General Procedure for the Synthesis of Compounds $\mathbf{1 6}$ and $\mathbf{1 7}$}

To a solution of benzisoselenazolone 19 and $20(1.0 \mathrm{mmol})$ in methanol $(10 \mathrm{~mL})$ cooled to $0{ }^{\circ} \mathrm{C}$, sodium borohydride $(1.0 \mathrm{mmol})$ was added and the mixture was stirred for $1 \mathrm{~h}$. Water $(15 \mathrm{~mL})$ was added and the mixture was oxidized with air for $1 \mathrm{~h}$. The formed precipitate was filtered and dried in air.

2,2'-Diselenobis(N-isobornylbenzamide) (17). Yield: $90 \%$, m.p. $148-150{ }^{\circ} \mathrm{C},[\alpha]_{\mathrm{D}}^{25}=-0.9\left(\mathrm{c} 1, \mathrm{CHCl}_{3}\right)$, ${ }^{1} \mathrm{H}-\mathrm{NMR}\left(400 \mathrm{MHz}, \mathrm{CDCl}_{3}\right) \delta=0.89\left(\mathrm{~s}, 6 \mathrm{H}, 2 \times \mathrm{CH}_{3}\right), 0.98\left(\mathrm{~s}, 6 \mathrm{H}, 2 \times \mathrm{CH}_{3}\right), 1.04\left(\mathrm{~s}, 6 \mathrm{H}, 2 \times \mathrm{CH}_{3}\right)$, 1.20-1.27 (m, 2H), 1.37-1.43 (m, 2H), 1.61-1.81 (m, 6H), $1.83(\mathrm{t}, J=4.4 \mathrm{~Hz}, 2 \mathrm{H}), 2.01(\mathrm{dd}, J=9.2,13.2 \mathrm{~Hz}$, $2 \mathrm{H}), 4.17(\mathrm{dt}, J=5.2,8.8 \mathrm{~Hz}, 2 \mathrm{H}), 6.14(\mathrm{~d}, J=8.8 \mathrm{~Hz}, 2 \mathrm{H}, 2 \times \mathrm{NH}), 7.22\left(\mathrm{dt}, J=1.2,7.2 \mathrm{~Hz}, 2 \mathrm{H}_{\mathrm{ar}}\right)$, $7.28\left(\mathrm{dt}, J=1.6,7.2 \mathrm{~Hz}, 2 \mathrm{H}_{\mathrm{ar}}\right), 7.41\left(\mathrm{dd}, J=1.6,7.6 \mathrm{~Hz}, 2 \mathrm{H}_{\mathrm{ar}}\right), 7.91\left(\mathrm{dd}, J=1.2,8.0 \mathrm{~Hz}, 2 \mathrm{H}_{\mathrm{ar}}\right) \mathrm{ppm}$; ${ }^{13} \mathrm{C}-\mathrm{NMR}\left(100.6 \mathrm{~Hz}, \mathrm{CDCl}_{3}\right) \delta=11.8\left(2 \times \mathrm{CH}_{3}\right), 20.2\left(2 \times \mathrm{CH}_{3}\right), 20.3\left(2 \times \mathrm{CH}_{3}\right), 27.0\left(2 \times \mathrm{CH}_{2}\right)$, $35.8\left(2 \times \mathrm{CH}_{2}\right), 39.0\left(2 \times \mathrm{CH}_{2}\right), 44.9(2 \times \mathrm{CH}), 47.2(2 \times \mathrm{C}), 48.9(2 \times \mathrm{C}), 57.4(2 \times \mathrm{CH}), 126.0\left(2 \times \mathrm{C}_{\mathrm{ar}}\right)$, $126.1\left(2 \times \mathrm{CH}_{\mathrm{ar}}\right), 131.4\left(2 \times \mathrm{CH}_{\mathrm{ar}}\right), 131.6\left(2 \times \mathrm{CH}_{\mathrm{ar}}\right), 133.0\left(2 \times \mathrm{C}_{\mathrm{ar}}\right), 133.5\left(2 \times \mathrm{C}_{\mathrm{ar}}\right), 167.4(2 \times \mathrm{C}=\mathrm{O}) \mathrm{ppm}$; ${ }^{77} \mathrm{Se}$ (76.3 MHz, DMSO), $\delta=450.58$ ppm; Elemental Anal. Calcd for $\mathrm{C}_{34} \mathrm{H}_{44} \mathrm{~N}_{2} \mathrm{O}_{2} \mathrm{Se}_{2}$ (670.645): C, 60.89; $\mathrm{H}, 6.61$. Found: C, 60.52; H, 6.55 .

2,2'-Diselenobis(N-bornylbenzamide) (18). Yield: 91\%, m.p. 208-210 ${ }^{\circ} \mathrm{C},[\alpha]_{\mathrm{D}}^{25}=-80.0\left(\right.$ c $\left.1, \mathrm{CHCl}_{3}\right)$, ${ }^{1} \mathrm{H}-\mathrm{NMR}\left(700 \mathrm{MHz}, \mathrm{CDCl}_{3}\right) \delta=0.94\left(\mathrm{~s}, 6 \mathrm{H}, 2 \times \mathrm{CH}_{3}\right), 1.00\left(\mathrm{~s}, 6 \mathrm{H}, 2 \times \mathrm{CH}_{3}\right), 1.09\left(\mathrm{~s}, 6 \mathrm{H}, 2 \times \mathrm{CH}_{3}\right)$, $1.41-1.47(\mathrm{~m}, 6 \mathrm{H}), 1.55-1.59(\mathrm{~m}, 2 \mathrm{H}), 1.81(\mathrm{t}, J=4.2 \mathrm{~Hz}, 2 \mathrm{H}), 1.92-1.95(\mathrm{~m}, 2 \mathrm{H}), 2.00-2.05(\mathrm{~m}, 2 \mathrm{H})$, $2.49-2.55(\mathrm{~m}, 2 \mathrm{H}), 5.06(\mathrm{ddd}, J=2.1,4.9, \mathrm{~Hz}, 2 \mathrm{H}, 2 \times \mathrm{NH}), 7.44(\mathrm{dt}, J=0.7,7.0 \mathrm{~Hz}, 2 \mathrm{H}$ ar $), 7.60(\mathrm{dt}, J=1.4$, $\left.5.6 \mathrm{~Hz}, 2 \mathrm{H}_{\mathrm{ar}}\right), 7.62-7.65\left(\mathrm{~m}, 2 \mathrm{H}_{\mathrm{ar}}\right), 8.06\left(\mathrm{dd}, J=0.7,7.7 \mathrm{~Hz}, 2 \mathrm{H}_{\mathrm{ar}}\right) \mathrm{ppm} ;{ }^{13} \mathrm{C}-\mathrm{NMR}\left(100.6 \mathrm{~Hz}, \mathrm{CDCl}_{3}\right)$ $\delta=13.8\left(2 \times \mathrm{CH}_{3}\right), 18.6\left(2 \times \mathrm{CH}_{3}\right), 19.8\left(2 \times \mathrm{CH}_{3}\right), 28.2\left(2 \times \mathrm{CH}_{2}\right), 28.4\left(2 \times \mathrm{CH}_{2}\right), 37.8\left(2 \times \mathrm{CH}_{2}\right)$, $44.9(2 \times \mathrm{CH}), 48.3(2 \times \mathrm{C}), 49.8(2 \times \mathrm{C}), 54.5(2 \times \mathrm{CH}), 126.0\left(2 \times \mathrm{CH}_{\mathrm{ar}}\right), 126.4\left(2 \times \mathrm{CH}_{\mathrm{ar}}\right), 131.4\left(2 \times \mathrm{CH}_{\mathrm{ar}}\right)$, $131.6\left(2 \times \mathrm{CH}_{\mathrm{ar}}\right), 132.8\left(2 \times \mathrm{C}_{\mathrm{ar}}\right), 133.8\left(2 \times \mathrm{C}_{\mathrm{ar}}\right), 168.3(2 \times \mathrm{C}=\mathrm{O}) \mathrm{ppm} ;{ }^{77} \mathrm{Se}(76.3 \mathrm{MHz}, \mathrm{DMSO})$, $\delta=450.03$ ppm; Elemental Anal. Calcd for $\mathrm{C}_{34} \mathrm{H}_{44} \mathrm{~N}_{2} \mathrm{O}_{2} \mathrm{Se}_{2}$ (670.645): $\mathrm{C}, 60.89 ; \mathrm{H}, 6.61$. Found: $\mathrm{C}, 60.63$; $\mathrm{H}, 6.64$.

\subsubsection{General Procedure for the Synthesis of Compounds 19 and 20}

Selenium powder $(1.2 \mathrm{mmol})$ and lithium hydroxide $(3.6 \mathrm{mmol})$ were weighed into a single neck flask under argon atmosphere and dissolved in DMF (3 mL). Hydrazine hydride $(8.0 \mathrm{mmol})$ was added dropwise, and the mixture was heated to $120^{\circ} \mathrm{C}$ and stirred for $15 \mathrm{~min}$. After cooling to room temperature, the amide $(1.0 \mathrm{mmol})$ dissolved in DMF $(2 \mathrm{~mL})$ was added. The reaction mixture was heated to $120^{\circ} \mathrm{C}$ and stirred for $20 \mathrm{~h}$ under argon atmosphere. The solution was cooled to room temperature and $25 \mathrm{~mL}$ of brine was added. The mixture was stirred for $20 \mathrm{~h}$. The obtained precipitate was filtered under vacume, washed with water, and dried in air. The crude product was purified by column chromatography (silica gel, DCM:MeOH 0.8:99.2).

N-Isobornyl-1,2-benzisoselenazol-3(2H)-one (19). Yield: 92\%, m.p. 205-207 ${ }^{\circ} \mathrm{C},[\alpha]_{\mathrm{D}}^{25}=-59.0\left(\right.$ c 1, $\left.\mathrm{CHCl}_{3}\right)$, ${ }^{1} \mathrm{H}-\mathrm{NMR}\left(400 \mathrm{MHz}, \mathrm{CDCl}_{3}\right) \delta=0.91\left(\mathrm{~s}, 3 \mathrm{H}, \mathrm{CH}_{3}\right), 0.93\left(\mathrm{~s}, 3 \mathrm{H}, \mathrm{CH}_{3}\right), 1.17\left(\mathrm{~s}, 3 \mathrm{H}, \mathrm{CH}_{3}\right), 1.25-1.34(\mathrm{~m}, 2 \mathrm{H})$, 
$1.63-1.71(\mathrm{~m}, 1 \mathrm{H}), 1.80-1.88(\mathrm{~m}, 2 \mathrm{H}), 2.00-2.07(\mathrm{~m}, 2 \mathrm{H}), 4.77(\mathrm{t}, J=8.4 \mathrm{~Hz}, 1 \mathrm{H}), 7.42(\mathrm{ddd}, J=2.0,6.0$, $\left.8.0 \mathrm{~Hz}, 1 \mathrm{H}_{\mathrm{ar}}\right), 7.55-7.60\left(\mathrm{~m}, 2 \mathrm{H}_{\mathrm{ar}}\right), 8.04\left(\mathrm{~d}, J=7.6 \mathrm{~Hz}, 1 \mathrm{H}_{\mathrm{ar}}\right) \mathrm{ppm} ;{ }^{13} \mathrm{C}-\mathrm{NMR}\left(100.6 \mathrm{~Hz}, \mathrm{CDCl}_{3}\right)$ $\delta=11.3\left(\mathrm{CH}_{3}\right), 21.2\left(\mathrm{CH}_{3}\right), 22.0\left(\mathrm{CH}_{3}\right), 26.5\left(\mathrm{CH}_{2}\right), 37.1\left(\mathrm{CH}_{2}\right), 39.3\left(\mathrm{CH}_{2}\right), 45.2(\mathrm{CH}), 46.7(\mathrm{C})$, $51.4(\mathrm{C}), 63.3(\mathrm{CH}), 123.2\left(\mathrm{CH}_{\mathrm{ar}}\right), 126.0\left(\mathrm{CH}_{\mathrm{ar}}\right), 128.5\left(\mathrm{C}_{\mathrm{ar}}\right), 128.7\left(\mathrm{CH}_{\mathrm{ar}}\right), 131.7\left(\mathrm{CH}_{\mathrm{ar}}\right), 138.2\left(\mathrm{C}_{\mathrm{ar}}\right)$, $168.6(\mathrm{C}=\mathrm{O}) \mathrm{ppm} ;{ }^{77} \mathrm{Se}\left(76.3 \mathrm{MHz}, \mathrm{CDCl}_{3}\right), \delta=866.07 \mathrm{ppm}$; Elemental Anal. Calcd for $\mathrm{C}_{17} \mathrm{H}_{21} \mathrm{NOSe}$ (334.315): C, 61.08; H, 6.33. Found: C, 61.29; H, 6.40.

N-Bornyl-1,2-benzisoselenazol-3(2H)-one (20). Yield: 90\%, m.p. $228-230{ }^{\circ} \mathrm{C},[\alpha]_{\mathrm{D}}^{25}=-64.3\left(\mathrm{c} 0.7, \mathrm{CHCl}_{3}\right)$, ${ }^{1} \mathrm{H}-\mathrm{NMR}\left(700 \mathrm{MHz}, \mathrm{CDCl}_{3}\right) \delta=0.91\left(\mathrm{~s}, 3 \mathrm{H}, \mathrm{CH}_{3}\right), 0.96\left(\mathrm{~s}, 3 \mathrm{H}, \mathrm{CH}_{3}\right), 1.06\left(\mathrm{~s}, 3 \mathrm{H}, \mathrm{CH}_{3}\right), 1.38-1.44(\mathrm{~m}, 3 \mathrm{H})$, $1.78(\mathrm{t}, J=4.2 \mathrm{~Hz}, 1 \mathrm{H}), 1.88-1.93(\mathrm{~m}, 1 \mathrm{H}), 1.97-2.01(\mathrm{~m}, 1 \mathrm{H}), 2.45-2.50(\mathrm{~m}, 1 \mathrm{H}), 5.03(\mathrm{ddd}, J=2.1$, $4.9,11.9 \mathrm{~Hz}, 1 \mathrm{H}), 7.41\left(\mathrm{dt}, J=1.4,7,7 \mathrm{~Hz}, 1 \mathrm{H}_{\mathrm{ar}}\right), 7.57\left(\mathrm{dt}, J=1.4,7,0 \mathrm{~Hz}, 1 \mathrm{H}_{\mathrm{ar}}\right), 7.60-7.63(\mathrm{~m}, 1 \mathrm{H})$, $8.02\left(\mathrm{~d}, J=7.7 \mathrm{~Hz}, 1 \mathrm{H}_{\mathrm{ar}}\right)$ ppm; ${ }^{13} \mathrm{C}-\mathrm{NMR}\left(100.6 \mathrm{~Hz}, \mathrm{CDCl}_{3}\right) \delta=14.2\left(\mathrm{CH}_{3}\right), 18.9\left(\mathrm{CH}_{3}\right), 19.9\left(\mathrm{CH}_{3}\right)$, $28.3\left(\mathrm{CH}_{2}\right), 28.6\left(\mathrm{CH}_{2}\right), 38.1\left(\mathrm{CH}_{2}\right), 45.2(\mathrm{CH}), 48.4(\mathrm{C}), 52.1(\mathrm{C}), 60.1(\mathrm{CH}), 123.2\left(\mathrm{CH}_{\mathrm{ar}}\right), 126.0\left(\mathrm{CH}_{\mathrm{ar}}\right)$, $128.3\left(\mathrm{C}_{\mathrm{ar}}\right), 128.7\left(\mathrm{CH}_{\mathrm{ar}}\right), 131.7\left(\mathrm{CH}_{\mathrm{ar}}\right), 138.0\left(\mathrm{C}_{\mathrm{ar}}\right), 168.3(\mathrm{C}=\mathrm{O}) \mathrm{ppm} ;{ }^{77} \mathrm{Se}\left(76.3 \mathrm{MHz}, \mathrm{CDCl}_{3}\right), \delta=877.38 \mathrm{ppm}$; Elemental Anal. Calcd for $\mathrm{C}_{17} \mathrm{H}_{21}$ NOSe (334.315): C, 61.08; H, 6.33. Found: $\mathrm{C}, 61.24 ; \mathrm{H}, 6.31$.

\subsubsection{Conversion of Diselenides to Benzisoselenazolones}

To a solution of diselenide $\mathbf{1 7}$ and $\mathbf{1 8}(1.0 \mathrm{mmol})$ in DMF $(3 \mathrm{~mL})$, under argon atmosphere, potassium iodate $(1.0 \mathrm{mmol})$ was added and the mixture was stirred at $120^{\circ} \mathrm{C}$ for $24 \mathrm{~h}$. The mixture was cooled to ambient temperature and brine $(5 \mathrm{~mL})$ was added. Mixture was stirred for $3 \mathrm{~h}$ and the formed precipitate was filtered and dried in air. Yield: 83\% (19), 86\% (20).

\subsubsection{Synthesis of 2,2-Diselenobis(benzoic acid) 6 and 2-(Chloroseleno)benzoyl Chloride 7}

To a suspension of selenium $(12.66 \mathrm{mmol})$ in water $(7 \mathrm{~mL})$ sodium borohydride $(25.32 \mathrm{mmol})$ was added under argon atmosphere. Mixture was stirred for $0.5 \mathrm{~h}$ at $0{ }^{\circ} \mathrm{C}$, selenium $(12.66 \mathrm{mmol})$ was added, and stirring was continued at the same temperature for $1 \mathrm{~h}$. Mixture was warmed to room temperature and stirred for $18 \mathrm{~h}$. After adding $10 \% \mathrm{NaOH}(5 \mathrm{~mL})$ the reaction was cooled to $5{ }^{\circ} \mathrm{C}$ and the diazonium salt of anthranilic acid was added dropwise. (The diazonium salt was prepared in advance- - to a solution of anthranilic acid $(25.96 \mathrm{mmol})$ and concentrated hydrochloric acid $(5 \mathrm{~mL})$ in water $(15 \mathrm{~mL})$ cooled to $5^{\circ} \mathrm{C}$ a cooled solution of sodium nitrite $(27.54 \mathrm{mmol})$ in water $(15 \mathrm{~mL})$ was added dropwise and the reaction was stirred for $15 \mathrm{~min}$ at $\left.5^{\circ} \mathrm{C}\right)$. The mixture was stirred for $3 \mathrm{~h}$ at $60^{\circ} \mathrm{C}$ and for $18 \mathrm{~h}$ at room temperature. The formed precipitate was filtred off and the solution was acidified to $\mathrm{pH}=1$ by $36 \% \mathrm{HCl}$. The formed precipitate was filtrated. The crude product 6 was purified by washing with boiling water and dried in air. Acid $6(0.01 \mathrm{mmol})$ was further converted to 2-(chloroseleno)benzoyl chloride 7 by heating with thionyl chloride $(20 \mathrm{~mL})$ at $85^{\circ} \mathrm{C}$ for $3 \mathrm{~h}$. Thionyl chloride was distilled off, and the crude product was used without further purification.

2,2-Diselenobis(benzoic acid) (6). Yield: 90\%, ${ }^{1} \mathrm{H}-\mathrm{NMR}(700.27 \mathrm{MHz}, \mathrm{DMSO}) \delta=7.35-7.37\left(\mathrm{~m}, 2 \mathrm{H}_{\mathrm{ar}}\right.$ ), $7.48-7.50\left(\mathrm{~m}, 2 \mathrm{H}_{\mathrm{ar}}\right), 7.67\left(\mathrm{dd}, J=8.4,0.7,2 \mathrm{H}, 2 \times \mathrm{CH}_{\mathrm{ar}}\right), 8.03\left(\mathrm{dd}, J=7.7,1.4,2 \mathrm{H}, 2 \times \mathrm{CH}_{\mathrm{ar}}\right)$, $13.72(\mathrm{~s}, 2 \mathrm{H}, 2 \times \mathrm{OH}) ;{ }^{13} \mathrm{C}-\mathrm{NMR}(100.6 \mathrm{~Hz}, \mathrm{DMSO}) \delta=126.9\left(2 \times \mathrm{CH}_{\mathrm{ar}}\right), 129.4\left(2 \times \mathrm{C}_{\mathrm{ar}}\right), 129.9\left(2 \times \mathrm{CH}_{\mathrm{ar}}\right)$, $131.9\left(2 \times \mathrm{CH}_{\mathrm{ar}}\right), 133.93\left(2 \times \mathrm{C}_{\mathrm{ar}}\right), 133.97\left(2 \times \mathrm{CH}_{\mathrm{ar}}\right), 169.0(2 \times \mathrm{C}=\mathrm{O}) \mathrm{ppm} ;{ }^{77} \mathrm{Se}(76.3 \mathrm{MHz}, \mathrm{DMSO})$, $\delta=441.09 \mathrm{ppm}$.

2-(Chloroseleno)benzoyl chloride (7). Yield 98\%; ${ }^{1} \mathrm{H}-\mathrm{NMR}\left(400.13 \mathrm{MHz}, \mathrm{CDCl}_{3}\right) \delta=7.50-7.54\left(\mathrm{~m}, 1 \mathrm{H}_{\mathrm{ar}}\right)$, $7.80-7.84\left(\mathrm{~m}, 1 \mathrm{H}_{\mathrm{ar}}\right), 8.12\left(\mathrm{dd}, J=8.4,0.8,1 \mathrm{H}, \mathrm{CH}_{\mathrm{ar}}\right), 8.37\left(\mathrm{dd}, J=8.0,1.2,1 \mathrm{H}, \mathrm{CH}_{\mathrm{ar}}\right) ;{ }^{13} \mathrm{C}-\mathrm{NMR}$ $\left(\mathrm{CDCl}_{3}, 100.62 \mathrm{MHz}\right) \delta=126.7\left(\mathrm{CH}_{\mathrm{ar}}\right), 127.1\left(\mathrm{CH}_{\mathrm{ar}}\right), 129.0\left(\mathrm{C}_{\mathrm{ar}}\right), 134.5\left(\mathrm{CH}_{\mathrm{ar}}\right), 136.2\left(\mathrm{CH}_{\mathrm{ar}}\right), 146.3\left(\mathrm{C}_{\mathrm{ar}}\right)$, $172.6\left(\mathrm{C}_{\mathrm{ar}}\right) ;{ }^{77} \mathrm{Se}-\mathrm{NMR}\left(\mathrm{CDCl}_{3}, 76.35 \mathrm{MHz}\right) \delta=1060.46 \mathrm{ppm}$.

\subsubsection{General Procedure for the Synthesis of Compounds 21-25}

To a solution of amine $(2.0 \mathrm{mmol})$ and triethylamine $(4.0 \mathrm{mmol})$ in dichloromethane 2-(chloroseleno)benzoyl chloride $(1.0 \mathrm{mmol})$ was added. The mixture was stirred for $24 \mathrm{~h}$ at room 
temperature, poured on water and extracted with DCM. The combined organic layers were dried over anhydrous magnesium sulfate and evaporated [22].

$\mathrm{N}$-(Glycine methyl ester)-benzisoselenazol-3(2H)-one (21). Yield 68\%; ${ }^{1} \mathrm{H}-\mathrm{NMR}\left(400.13 \mathrm{MHz}, \mathrm{CDCl}_{3}\right)$ $\delta=3.80-3.81(\mathrm{~m}, 3 \mathrm{H}), 4.61-4.62(\mathrm{~d}, J=4.0,2 \mathrm{H}), 7.43-7.45\left(\mathrm{~m}, 1 \mathrm{H}_{\mathrm{ar}}\right), 7.61-7.68\left(\mathrm{~m}, 2 \mathrm{H}_{\mathrm{ar}}\right), 8.06-8.08\left(\mathrm{~m}, 1 \mathrm{H}_{\mathrm{ar}}\right)$; ${ }^{13} \mathrm{C}-\mathrm{NMR}\left(176.10 \mathrm{MHz}, \mathrm{CDCl}_{3}\right) \delta=45.0\left(\mathrm{CH}_{2}\right), 52.2\left(-\mathrm{OCH}_{3}\right), 123.6\left(\mathrm{CH}_{\mathrm{ar}}\right), 125.6\left(\mathrm{C}_{\mathrm{ar}}\right), 125.9\left(\mathrm{CH}_{\mathrm{ar}}\right)$, $128.6\left(\mathrm{CH}_{\mathrm{ar}}\right), 132.0\left(\mathrm{CH}_{\mathrm{ar}}\right), 138.5\left(\mathrm{C}_{\mathrm{ar}}\right), 167.4(\mathrm{C}=\mathrm{O}), 168.7(\mathrm{C}=\mathrm{O}) ;{ }^{77} \mathrm{Se}-\mathrm{NMR}\left(76.35 \mathrm{MHz}, \mathrm{CDCl}_{3}\right)$ $\delta=937.49 \mathrm{ppm}$.

$\mathrm{N}$-(Alanine methyl ester)-benzisoselenazol-3(2H)-one (22). Yield; $84 \% ;{ }^{1} \mathrm{H}-\mathrm{NMR}\left(700.27 \mathrm{MHz}, \mathrm{CDCl}_{3}\right)$ $\delta=1.58\left(\mathrm{~d}, J=7.0,3 \mathrm{H}, \mathrm{CH}_{3}\right), 3.74\left(\mathrm{~s}, 3 \mathrm{H},-\mathrm{OCH}_{3}\right), 5.42(\mathrm{q}, J=7.0,1 \mathrm{H}, \mathrm{CH}), 7.40-7.42\left(\mathrm{~m}, 1 \mathrm{H}_{\mathrm{ar}}\right), 7.58-7.60$ $\left(\mathrm{m}, 1 \mathrm{H}_{\mathrm{ar}}\right), 7.64-7.65\left(\mathrm{~m}, 1 \mathrm{H}_{\mathrm{ar}}\right), 8.05\left(\mathrm{~d}, J=7.7,1 \mathrm{H}, \mathrm{CH}_{\mathrm{ar}}\right) ;{ }^{13} \mathrm{C}-\mathrm{NMR}\left(100.62 \mathrm{MHz}, \mathrm{CDCl}_{3}\right) \delta=18.7\left(\mathrm{CH}_{3}\right)$, 51.6 $\left(-\mathrm{OCH}_{3}\right), 52.7(\mathrm{CH}), 123.8\left(\mathrm{CH}_{\mathrm{ar}}\right), 126.2\left(\mathrm{CH}_{\mathrm{ar}}\right), 126.9\left(\mathrm{C}_{\mathrm{ar}}\right), 128.8\left(\mathrm{CH}_{\mathrm{ar}}\right), 132.2\left(\mathrm{CH}_{\mathrm{ar}}\right), 139.2\left(\mathrm{C}_{\mathrm{ar}}\right)$, $167.5(\mathrm{C}=\mathrm{O}), 172.2(\mathrm{C}=\mathrm{O}) ;{ }^{77} \mathrm{Se}-\mathrm{NMR}\left(76.35 \mathrm{MHz}, \mathrm{CDCl}_{3}\right) \delta=888.79 \mathrm{ppm}$.

$\mathrm{N}$-(Leucine methyl ester)-benzisoselenazol-3(2H)-one (23). Yield 83\%; ${ }^{1} \mathrm{H}-\mathrm{NMR}\left(700.27 \mathrm{MHz}, \mathrm{CDCl}_{3}\right)$ $\delta=0.96\left(\mathrm{~d}, J=6.3,3 \mathrm{H}, \mathrm{CH}_{3}\right) 0.97\left(\mathrm{~d}, J=7,3 \mathrm{H}, \mathrm{CH}_{3}\right), 1.53-1.59(\mathrm{~m}, 1 \mathrm{H}), 1.75-1.85(\mathrm{~m}, 2 \mathrm{H})$, $3.75\left(\mathrm{~s}, 3 \mathrm{H},-\mathrm{OCH}_{3}\right), 5.44-5.46(\mathrm{~m}, 1 \mathrm{H}), 7.40-7.42\left(\mathrm{~m}, 1 \mathrm{H}_{\mathrm{ar}}\right), 7.59\left(\mathrm{dt}, J=7.0,1.4,1 \mathrm{H}, \mathrm{CH}_{\mathrm{ar}}\right)$, $7.63\left(\mathrm{~d}, J=7.7,1 \mathrm{H}, \mathrm{CH}_{\mathrm{ar}}\right), 8.05\left(\mathrm{dd}, J=7.7,0.7,1 \mathrm{H}, \mathrm{CH}_{\mathrm{ar}}\right) ;{ }^{13} \mathrm{C}-\mathrm{NMR}\left(176.10 \mathrm{MHz}, \mathrm{CDCl}_{3}\right)$ $\delta=22.6\left(\mathrm{CH}_{3}\right), 23.9\left(\mathrm{CH}_{3}\right), 25.6(\mathrm{CH}), 43.2\left(\mathrm{CH}_{2}\right), 53.5\left(-\mathrm{OCH}_{3}\right), 55.2(\mathrm{CH}), 124.9\left(\mathrm{CH}_{\mathrm{ar}}\right), 127.1\left(\mathrm{CH}_{\mathrm{ar}}\right)$, $127.9\left(\mathrm{C}_{\mathrm{ar}}\right), 129.9\left(\mathrm{CH}_{\mathrm{ar}}\right), 133.2\left(\mathrm{CH}_{\mathrm{ar}}\right), 140.0\left(\mathrm{C}_{\mathrm{ar}}\right), 168.6(\mathrm{C}=\mathrm{O}), 173.1(\mathrm{C}=\mathrm{O}) ;{ }^{77} \mathrm{Se}-\mathrm{NMR}(76.35 \mathrm{MHz}$, $\left.\mathrm{CDCl}_{3}\right) \delta=886.93 \mathrm{ppm}$.

$\mathrm{N}$-(Phenylalanine methyl ester)-benzisoselenazol-3(2H)-one (24). Yield 98\%; ${ }^{1} \mathrm{H}-\mathrm{NMR}\left(700.27 \mathrm{MHz}, \mathrm{CDCl}_{3}\right)$ $\delta=3.15-3.18(\mathrm{~m}, 1 \mathrm{H}), 3.33-3.36(\mathrm{~m}, 1 \mathrm{H}), 3.70\left(\mathrm{~s}, 3 \mathrm{H},-\mathrm{OCH}_{3}\right), 5.62-5.64(\mathrm{~m}, 1 \mathrm{H}), 7.19-7.261(\mathrm{~m}, 5 \mathrm{H})$, $7.38\left(\mathrm{dt}, J=7.0,0.7,1 \mathrm{H}, \mathrm{CH}_{\mathrm{ar}}\right), 7.56-7.62\left(\mathrm{~m}, 2 \mathrm{H}_{\mathrm{ar}}\right), 8.00\left(\mathrm{dd}, J=7.7,0.7,1 \mathrm{H}, \mathrm{CH}_{\mathrm{ar}}\right) ;{ }^{13} \mathrm{C}-\mathrm{NMR}$ $\left(100.62 \mathrm{MHz}, \mathrm{CDCl}_{3}\right) \delta=39.1\left(\mathrm{CH}_{2}\right), 52.5\left(-\mathrm{OCH}_{3}\right), 57.2(\mathrm{CH}), 123.7\left(\mathrm{CH}_{\mathrm{ar}}\right), 126.1\left(\mathrm{CH}_{\mathrm{ar}}\right), 126.6\left(\mathrm{C}_{\mathrm{ar}}\right)$, $127.2\left(\mathrm{CH}_{\mathrm{ar}}\right), 128.6\left(2 \times \mathrm{CH}_{\mathrm{ar}}\right), 128.8\left(\mathrm{CH}_{\mathrm{ar}}\right), 129.1\left(2 \times \mathrm{CH}_{\mathrm{ar}}\right), 132.2\left(\mathrm{CH}_{\mathrm{ar}}\right), 135.5\left(\mathrm{C}_{\mathrm{ar}}\right), 139.3\left(\mathrm{C}_{\mathrm{ar}}\right)$, $167.5(\mathrm{C}=\mathrm{O}), 171.4(\mathrm{C}=\mathrm{O}){ }^{77} \mathrm{Se}-\mathrm{NMR}\left(76.35 \mathrm{MHz}, \mathrm{CDCl}_{3}\right) \delta=904.16 \mathrm{ppm}$.

$\mathrm{N}$-(Alanine carboxyl acid)-benzisoselenazol-3(2H)-one (25). Yield 63\%; ${ }^{1} \mathrm{H}-\mathrm{NMR}\left(400.13 \mathrm{MHz}, \mathrm{CDCl}_{3}\right)$ $\delta=2.73-2.78(\mathrm{~m}, 2 \mathrm{H}), 4.10\left(\mathrm{t}, J=6.4,2 \mathrm{H}, \mathrm{CH}_{2}\right), 7.44\left(\mathrm{t}, J=7.2,1 \mathrm{H}, \mathrm{CH}_{\mathrm{ar}}\right), 7.60-7.64\left(\mathrm{~m}, 1 \mathrm{H}_{\mathrm{ar}}\right), 7.91-7.94$ $\left(\mathrm{m}, 2 \mathrm{H}_{\mathrm{ar}}\right) ;{ }^{13} \mathrm{C}-\mathrm{NMR}\left(100.62 \mathrm{MHz}, \mathrm{CDCl}_{3}\right) \delta=34.0\left(\mathrm{CH}_{2}\right), 40.1\left(\mathrm{CH}_{2}\right), 124.8\left(\mathrm{CH}_{\mathrm{ar}}\right), 125.7\left(\mathrm{CH}_{\mathrm{ar}}\right)$, 127.2 $\left(\mathrm{C}_{\mathrm{ar}}\right), 127.3\left(\mathrm{CH}_{\mathrm{ar}}\right), 131.7\left(\mathrm{CH}_{\mathrm{ar}}\right), 168.0(\mathrm{C}=\mathrm{O}), 172.1(\mathrm{C}=\mathrm{O}) ;{ }^{77} \mathrm{Se}-\mathrm{NMR}\left(76.35 \mathrm{MHz}, \mathrm{CDCl}_{3}\right)$ $\delta=922.33 \mathrm{ppm}$.

\subsection{Antioxidant Activity Assay}

To a solution of compounds and 17-25 $(0.015 \mathrm{mmol})$ and dithiothreitole DTT ${ }^{\text {red }}(0.15 \mathrm{mmol})$ in $1.1 \mathrm{~mL}$ of $\mathrm{CD}_{3} \mathrm{OD} 30 \% \mathrm{H}_{2} \mathrm{O}_{2}(0.15 \mathrm{mmol})$ was added. ${ }^{1} \mathrm{H}-\mathrm{NMR}$ spectra were measuared right after addition of hydrogen peroxide and then in specific time intervals. The concentration of the substrate was determined according to the changes in the integration on the ${ }^{1} \mathrm{H}-\mathrm{NMR}$ spectra [43].

\subsection{Cell Viability Assays}

\subsubsection{MTT Viability Assay}

\section{Cell Culture}

The HL-60, MCF-7, and HepG2 cell lines were purchased from the European Collection of Cell Cultures (ECACC, Salisbury, UK). HL-60 cells were cultured in RPMI 1640 plus GlutaMax I medium (Invitrogen, Grand Island, NY, USA), supplemented with 10\% heat-inactivated FBS (Biological Industries, Beit-Haemek, Israel) and antibiotics $(100 \mu \mathrm{g} / \mathrm{mL}$ streptomycin and $100 \mathrm{U} / \mathrm{mL}$ penicillin) (Sigma Aldrich, St. Louis, MO, USA). MCF-7 and HepG2 cells were cultured in MEME (Sigma-Aldrich, St. Louis, MO, USA), supplemented with 10\% FBS (Biological Industries, 
Beit-Haemek, Israel), $2 \mathrm{mM}$ glutamine, Men Non-essential amino acid solution and antibiotics (100 mg/mL streptomycin and $100 \mathrm{U} / \mathrm{mL}$ penicillin), all from Sigma Aldrich (St. Louis, MO, USA). Cells were maintained at $37^{\circ} \mathrm{C}$ in a $5 \% \mathrm{CO}_{2}$ atmosphere and were grown until $80 \%$ confluent.

\section{MTT Assay}

The MTT (3-(4,5-dimethyldiazol-2-yl)-2,5 diphenyl tetrazolium bromide) assay, which measures activity of cellular dehydrogenases, was based on the method of Mosmann [46]. Briefly, cells were seeded into 96-well plates (about $1.5 \times 104$ cells per well, in $100 \mu \mathrm{L}$ ) and then left to adhere and grow for $24 \mathrm{~h}$. Subsequently, $100 \mu \mathrm{L}$ of the tested compounds in the medium were added to a final concentration of $0-250 \mu \mathrm{M}$, and kept for $48 \mathrm{~h}$, followed by the addition of $100 \mu \mathrm{L} \mathrm{MTT,} 3 \mathrm{mg} / \mathrm{mL}$ in PBS, for the next $3 \mathrm{~h}$. After the incubation, the medium was removed. Remaining insoluble formazan crystals were dissolved in $100 \mu \mathrm{L}$ DMSO. The absorbance of the blue formazan product was measured at $570 \mathrm{~nm}$ in the plate reader spectrophotometer Infinite M200 (Tecan, Grödig, Austria) and compared with control (untreated cells). All experiments were performed three times in triplicate. The concentration of tested compounds required to inhibit cell viability by $50 \%\left(\mathrm{IC}_{50}\right)$ was calculated using Microsoft Excel software for semi-log curve fitting with linear regression analysis.

\subsubsection{SRB Viability Assay}

\section{Cell Culture}

The prostate cancer cell line DU-145 was purchased from the American Type Culture Collection (ATTC, Manassas, VA, USA). The DU- 145 cells were cultured in MEME medium supplemented with $10 \%$ fetal bovine serum, $1 \%$ penicillin/streptomycin, $2 \mathrm{mM}$ glutamine and $1 \mathrm{mM}$ sodium pyruvate at $37^{\circ} \mathrm{C}$. The PNT1A cells were cultured in RPMI 1640 supplemented with serum, L-glutamine and antibiotics. The cells were maintained at $37{ }^{\circ} \mathrm{C}$ in an atmosphere containing $5 \% \mathrm{CO}_{2}$. Stock solutions of $\mathrm{N}$-substituted ebselen derivatives were prepared in (0.1\%) DMSO.

\section{SRB Assay}

Cell viability was measured by Sulphorhodamine B (SRB) assay. The cells were grown to sub-confluent levels at the certain culture medium and then seeded into 96-well plates at $6.0 \times 10^{3}$ cells/well in the final volume of $200 \mu \mathrm{L}$ in the culture medium for $24 \mathrm{~h}$. Then, they were treated with various concentrations $(2.5,5,10,20,30$, and $40 \mu \mathrm{M})$ of $N$-substituted ebelsen derivatives for the next $24 \mathrm{~h}$. After incubation, the cells were fixed in $20 \%$ trichloroacetic acid for an $1 \mathrm{~h}$. The plates were washed with distilled water, and $0.4 \%$ SRB (Sigma-Aldrich, St. Louis, MO, USA) in 1\% acetic acid solution was added to the plates for $15 \mathrm{~min}$. The SRB solution was washed with 1\% acetic acid. SRB was then solubilized in $10 \mathrm{mM}$ Trisma-base solution and the absorbance was measured at $570 \mathrm{~nm}$ using an automated microplate reader. The experiments were done in triplates and the $\mathrm{IC}_{50}$ values were calculated.

\section{Conclusions}

In this paper, we synthetized the first optically active ebselen analogues derived from terpenes 17-20. Additionally, we presented an improved version of the known procedure involving the synthesis of 2,2-diselenobis(benzoic acid) 6 and proved that the cyclization of the Se-N bond depends on the nucleophilic selenium reagent used. Antioxidant and anticancer activities of $\mathrm{N}$-bornyl 20 and $N$-isobornyl 19 benzisoselenazol-3(2H)-ones and corresponding diselenides 17, 18 were evaluated and compared to a series of $N$-amino acid ebselen analogues 21-25. The highest antioxidant potential was observed for benzisoselenazol-3(2H)-ones substituted with $N$-bornyl 20 and $\mathrm{N}$-leucine methyl ester $\mathbf{2 3}$ moieties. Select reactive derivatives were tested as anticancer agents on four cancer cell lines. The highest antiproliferative activity was observed for $N$-leucine methyl ester benzisoselenazol-3(2H)-one 23. Additionally, we tested antiproliferative activity for ebselen with 3-methylbutyl carbon chain 26. The data suggest that the basic structural skeleton 
connecting 3-methylbutyl carbon chain can be a pharmacophore necessary for the antioxidant and anticancer activity.

Supplementary Materials: Supplementary materials are available online.

Acknowledgments: This work was supported by the National Science Centre, Poland, grant No. UMO-2015/17/ B/NZ7/03058.

Author Contributions: A.J.P. and J.Ś. conceived and designed the experiments, discussed the results, and wrote the paper; K.B.K. and J.A. performed the SRB viability assays; A.J., A.D. and T.J. performed the MTT viability assays; A.W. performed and analyzed X-ray data. All authors read and approved the final version of the manuscript.

Conflicts of Interest: The authors declare no conflict of interest.

\section{References}

1. Parnham, J.M.; Sies, H. The early research and development of ebselen. Biochem. Pharm. 2013, 86, 1248-1253. [CrossRef] [PubMed]

2. Bhujan, B.J.; Mugesh, G. Biological and Biochemical Aspects of Selenium Compounds. In Organoselenium Chemistry; Wirth, T., Ed.; Wiley-VCH: Weinheim, Germany, 2012.

3. Soares, J.C.M.; Folmer, V.; da Rocha, J.B.T.; Nogueira, C.W. Ebselen exhibits glycation-inhibiting properties and protects against osmotic fragility of human erythrocytes in vitro. Cell. Biol. Int. 2014, 38, 625-630. [CrossRef] [PubMed]

4. Park, S.; Kang, S.; Kim, D.S.; Shin, B.K.; Moon, N.R.; Daily, J.W., III. Ebselen pretreatment attenuates ischemia/reperfusion injury and prevents hyperglycemia by improving hepatic insulin signaling and $\beta$-cell survival in gerbils. Free Radic. Res. 2014, 48, 864-874. [CrossRef] [PubMed]

5. Wang, X.; Yun, J.-W.; Lei, X.G. Glutathione peroxidase mimic ebselen improves glucose-stimulated insulin secretion in murine islets. Antioxid. Redox Signal. 2014, 20, 191-203. [CrossRef] [PubMed]

6. Tan, S.M.; Sharma, A.; Yuen, D.Y.C.; Stefanovic, N.; Krippner, G.; Mugesh, G.; Chai, Z.; de Haan, J.B. The Modified Selenenyl Amide, M-hydroxy Ebselen, Attenuates Diabetic Nephropathy and Diabetes-Associated Atherosclerosis in ApoE/GPx1 Double Knockout Mice. PLoS ONE 2013, 8, e69193. [CrossRef] [PubMed]

7. Martini, F.; Bruning, C.A.; Soares, S.M.; Nogueira, C.W.; Zeni, G. Inhibitory Effect of Ebselen on Cerebral Acetylcholinesterase Activity In Vitro: Kinetics and Reversibility of Inhibition. Curr. Pharm. Des. 2015, 21, 920-924. [CrossRef] [PubMed]

8. Lynch, E.D.; Kill, J. Compounds for the prevention and treatment of noise-induced hearing loss. Drug Discov. Today 2005, 10, 1291-1298. [CrossRef]

9. Yamaguchi, T.; Sano, K.; Takakura, K.; Saito, I.; Shinohara, Y.; Asano, T.; Yasuhara, H. Ebselen in Acute Ischemic Stroke. A Placebo-Controlled, Double-blind Clinical Trial. Stroke 1998, 29, 12-17. [CrossRef] [PubMed]

10. Zhang, L.; Zhou, L.; Du, J.; Li, M.; Qian, C.; Cheng, Y.; Peng, Y.; Xie, J.; Wang, D. Induction of Apoptosis in Human Multiple Myeloma Cell Lines by Ebselen via Enhancing the Endogenous Reactive Oxygen Species Production. BioMed Res. Int. 2014, 2014, 696107. [CrossRef] [PubMed]

11. Pacuła, A.J.; Mangiavacchi, F.; Sancineto, L.; Lenardao, E.J.; Ścianowski, J.; Santi, C. An Update on "Selenium Containing Compounds from Poison to Drug Candidates: A Review on the GPx-like Activity". Curr. Chem. Biol. 2015, 9, 97-112. [CrossRef]

12. Orian, L.; Toppo, S. Organochalcogen peroxidase mimetics as potential drugs: A long story of a promise still unfulfilled. Free Radic. Biol. Med. 2014, 66, 65-74. [CrossRef] [PubMed]

13. Mugesh, G. Glutathione Peroxidase Activity of Ebselen and its Analogues: Some Insights into the Complex Chemical Mechanisms Underlying the Antioxidant Activity. Curr. Med. Chem. 2013, 7, 47-56. [CrossRef]

14. Pacuła, A.J.; Kaczor, K.B.; Wojtowicz, A.; Antosiewicz, J.; Janecka, A.; Długosz, A.; Janecki, T.; Ścianowski, J. New glutathione peroxidase mimetics-Insights into antioxidant and cytotoxic activity. Bioorg. Med. Chem. 2017, 25, 126-131.

15. Welter, A.; Christiaens, L.; Ferdinand, W.P. New Benzisoselenazolones, Process for Producing the Same and Pharmaceutical Preparations Containing the Same. EP 0044453 A2, 27 January 1982.

16. Engman, L.; Hallberg, A. Expedient synthesis of ebselen and related compounds. J. Org. Chem. 1989, 54, 2964-2966. [CrossRef] 
17. Balkrishna, S.J.; Bhakuni, B.S.; Chopra, D.; Kumar, S. Cu-catalyzed efficient synthetic methodology for ebselen and related Se-N heterocycles. Org. Lett. 2010, 12, 5394-5397. [CrossRef] [PubMed]

18. Balkrishna, S.J.; Kumar, S.; Azad, K.G.; Bhakuni, B.S.; Panini, P.; Ahalawat, N.; Tomar, R.S.; Detty, R.M.; Kumar, S. An ebselen like catalyst with enhanced GPx activity via a selenol intermediate. Org. Biomol. Chem. 2014, 12, 1215-1219. [CrossRef] [PubMed]

19. Pacuła, A.J.; Ścianowski, J.; Aleksandrzak, K.B. Highly efficient synthesis and antioxidant capacity of N-substituted benzisoselenazol-3(2H)-ones. RSC Adv. 2014, 4, 48959-48962. [CrossRef]

20. Elsherbini, M.; Hamama, W.S.; Zoorob, H.H.; Bhowmick, D.; Mugesh, G.; Wirth, T. Synthesis and antioxidant activities of novel chiral ebselen analogues. Heteroatom Chem. 2014, 25, 320-325. [CrossRef]

21. Satheeshkumar, K.; Mugesh, G. Synthesis and Antioxidant Activity of Peptide-Based Ebselen Analogues. Chem. Eur. J. 2011, 17, 4849-4857. [CrossRef] [PubMed]

22. Mlochowski, J.; Gryglewski, R.J.; Inglot, A.D.; Jakubowski, A.; Juchniewicz, L.; Kloc, K. Synthesis and Properties of 2-Carboxyalkyl-1,2-benzisoselenazol-3(2H)-ones and Related Organoselenium Compounds as Nitric Oxide Synthase Inhibitors and Cytokine Inducers. Liebigs Ann. 1996, 1996, 1751-1755. [CrossRef]

23. Pacuła, A.J.; Ścianowski, J. Terpenes as Green Starting Materials for New Organoselenium and Organotellurium Compounds. Curr. Green Chem. 2016, 3, 36-50. [CrossRef]

24. Ścianowski, J.; Rafalski, J.; Banach, A.; Czaplewska, J.; Komoszyńska, A. Synthesis and reactions of the optically active selenols derived from monoterpenes. Tetrahedron Asymmetry 2013, 24, 1089-1096. [CrossRef]

25. Rafiński, Z.; Ścianowski, J. Synthesis and reactions of enantiomerically pure dialkyl diselenides from the p-menthane group. Tetrahedron Asymmetry 2008, 19, 1237-1244. [CrossRef]

26. Ścianowski, J.; Rafinski, Z.; Wojtczak, A.; Burczynski, K. Syntheses and reactions of terpene $\beta$-hydroxyselenides and $\beta$-hydroxydiselenides. Tetrahedron Asymmetry 2009, 20, 2871-2879. [CrossRef]

27. Ścianowski, J. Convenient route to dialkyl diselenides from alkyl tosylates. Synthesis of Di(cis-myrtanyl) diselenide. Tetrahedron Lett. 2005, 46, 3331-3334. [CrossRef]

28. Ścianowski, J.; Rafiński, Z.; Wojtczak, A. Syntheses and Reactions of New Optically Active Terpene Dialkyl Diselenides. Eur. J. Org. Chem. 2006, 14, 3216-3225. [CrossRef]

29. Ścianowski, J.; Banach, A.; Uzarewicz-Baig, M.; Wojtczak, A. Terpenyl Selenides: Synthesis and Application in Asymmetric Epoxidation. Eur. J. Org. Chem. 2015, 16, 3477-3485.

30. Rafinski, Z.; Ścianowski, J.; Wojtczak, A. Synthesis and Reactions of the Optically Active Dialkyl Diselenides from the Pinane Group. Lett. Org. Chem. 2009, 6, 321-328. [CrossRef]

31. Ścianowski, J.; Rafiński, Z.; Szuniewicz, A.; Wojtczak, A. New chiral selenium electrophiles derived from functionalized terpenes. Tetrahedron 2009, 65, 10162-10174. [CrossRef]

32. Flack, H.D. On enantiomorph-polarity estimation. Acta Cryst. 1983, A39, 876-881. [CrossRef]

33. Allen, H. The Cambridge Structural Database: A quarter of a million crystal structures and rising. Acta Cryst. 2002, B58, 380-388. [CrossRef]

34. Selvakumar, K.; Singh, H.B.; Butcher, R.J. Strained dimethyl 2-(bromoselanyl)-5-tert-butylisophthalate: A reactive precursor for the synthesis of ebselen analogs. Tetrahedron Lett. 2011, 52, 6831-6834. [CrossRef]

35. Bhabak, K.P.; Vernekar, A.A.; Jakka, S.R.; Roy, G.; Mugesh, G. Mechanistic investigations on the efficient catalytic decomposition of peroxynitrite by ebselen analogues. Org. Biomol. Chem. 2011, 9, 5193-5200. [CrossRef] [PubMed]

36. Bhabak, K.P.; Mugesh, G. Synthesis, characterization, and antioxidant activity of some ebselen analogues. Chem. Eur. J. 2007, 13, 4594-4601. [CrossRef]

37. Piatek, M.; Oleksyn, B.; Sliwinski, J. 2-Methyl-2H-1,2-benzisoselenazol-3-one. Acta Crystallogr. Sect. 1995, C51, 298-301. [CrossRef]

38. Zade, S.S.; Panda, S.; Tripathi, S.K.; Singh, H.B.; Wolmershäuser, G. Convenient Synthesis, Characterization and GPx-Like Catalytic Activity of Novel Ebselen Derivatives. Eur. J. Org. Chem. 2004, 2004, 3857-3864. [CrossRef]

39. Syper, L.; Młochowski, J. The Convenient Syntheses of Organoselenium Reagents. Synthesis 1984, 1984, 439-442. [CrossRef]

40. Bird, M.L.; Challenger, F. Potassium alkaneselenonates and other alkyl derivatives of selenium. J. Chem. Soc. 1942, 570-574. [CrossRef] 
41. Klayman, D.L.; Griffin, T.S. Reaction of selenium with sodium borohydride in protic solvents. A Facile Method for the introduction of selenium into organic molecules. J. Am. Chem. Soc. 1973, 95, 197-199. [CrossRef]

42. Lou, Z.; Li, P.; Sun, X.; Yang, S.; Wang, B.; Han, K. A fluorescent probe for rapid detection of thiols and imaging of thiols reducing repair and hydrogen peroxide oxidative stress cycles in living cells. Chem. Commun. 2013, 49, 391-393. [CrossRef] [PubMed]

43. Kumakura, F.; Mishra, B.; Priyadarsini, K.I.; Iwaoka, M. A Water-Soluble Cyclic Selenide with Enhanced Glutathione Peroxidase-Like Catalytic Activities. Eur. J. Org. Chem. 2010, 3, 440-444. [CrossRef]

44. Rao, M.N.; Haridas, M.; Gangwar, M.K.; Rajakannu, P.; Kalita, A.C.; Ghosh, P. Asymmetric Base-Free Michael Addition at Room Temperature with Nickel-Based Bifunctional Amido-Functionalized N-Heterocyclic Carbene Catalysts. Eur. J. Inorg. Chem. 2015, 9, 1604-1615. [CrossRef]

45. Dickmu, G.C.; Stahl, L.; Smoliakovaet, I.P. A new enantiopure D-camphor-derived palladacycle. J. Organomet. Chem. 2014, 756, 27-33. [CrossRef]

46. Mosmann, T. Rapid colorimetric assay for cellular growth and survival: Application to proliferation and cytotoxicity assays. J. Immunol. Methods 1983, 65, 55-63. [CrossRef]

Sample Availability: Samples of the compounds are not available from the authors.

(C) 2017 by the authors. Licensee MDPI, Basel, Switzerland. This article is an open access article distributed under the terms and conditions of the Creative Commons Attribution (CC BY) license (http:/ / creativecommons.org/licenses/by/4.0/). 